\title{
Haemodynamic, hormonal, and electrolyte effects of enalapril in heart failure
}

\author{
DREW FITZPATRICK, M GARY NICHOLLS, HAMID IKRAM, ERIC A ESPINER \\ From the Cardiology and Endocrinology Departments, The Princess Margaret Hospital, Christchurch, New Zealand
}

SUMmaRY Enalapril, the new converting enzyme inhibitor, was administered to eight patients with heart failure (NYHA Functional Class II to IV) during standardised and intensive haemodynamic, hormone, and electrolyte monitoring. The first dose $(5 \mathrm{mg})$ of enalapril induced a fall in plasma angiotensin II and noradrenaline levels, and prolonged decrements in systemic vascular resistance, arterial pressure, heart rate, and right heart pressures. Maximum haemodynamic effects were evident four to eight hours after the first dose, with return to baseline by 24 hours. Plasma angiotensin II levels, however, were still suppressed at 24 hours. The magnitude of haemodynamic response was related closely to baseline (pre-enalapril) activity of the renin-angiotensin system and the sympathetic system. Enalapril treatment over three days induced a positive cumulative balance of sodium and potassium, and a small increase in plasma potassium. Urine aldosterone excretion decreased in a stepwise fashion. Continued enalapril administration for four to eight weeks resulted in improved clinical status (NYHA Functional Class) and exercise tolerance in patients who initially were most severely incapacitated, but little change was observed in healthier subjects. We conclude that in heart failure, enalapril is a long acting converting enzyme inhibitor with clear cut beneficial haemodynamic effects in the short term. Long term controlled studies of enalapril in heart failure are warranted.

Inhibition of the angiotensin converting enzyme with captopril has proved effective in the treatment of patients with resistant heart failure. ${ }^{2} \mathrm{~A}$ new class of converting enzyme inhibitors has recently been developed $^{3}$ to avoid specific side effects of captopril related to the mercapto moiety of the drug. One such agent, enalapril (MK-421), appears effective in the treatment of human hypertension, ${ }^{4}$ but its effects in patients with heart failure have not been assessed. The purpose of the present study is to document short term haemodynamic, hormone, and electrolyte responses to enalapril in patients with heart failure.

\section{Patients and methods}

The procedure was approved by the Hospital's Ethical Committee, and all patients gave informed written consent. Clinical details of the eight patients are summarised in Table 1. Vasodilators were withdrawn at least four days before the study, but digoxin (0.125 to $0.25 \mathrm{mg} /$ day) was continued at constant dose throughout the study. Frusemide (Table 2) was stopped five days before the study in two patients whereas Accepted for publication 7 April 1983 the other six were maintained on a constant diuretic dose during the in-patient period.

The procedure involved an initial control period of two days followed by three days of incremental enalapril administration: 5,10 , and $20 \mathrm{mg}$ given at 0900 hours on days 3,4 , and 5, respectively. Placebo tablets were not given on the control days. Throughout the study and for two days before its initiation, each patient received a diet of constant sodium (91 to $116 \mathrm{mmol} /$ day) and potassium (54 to $67 \mathrm{mmol} /$ day) content. Meals were taken at 0915,1215 , and 1815 hours. All urine was collected on ice for electrolyte and hormone analysis. The patients remained semisupine throughout. On the afternoon before day 1 , a triple-lumen Swan-Ganz catheter was placed in the pulmonary artery for right heart pressure and cardiac output measurements, and a radial or brachial artery cannula was inserted for pressure recordings and for plasma hormone and electrolyte sampling. Details of haemodynamic recording and hormone measurement techniques have been reported previously. ${ }^{1}$ To document detailed information of first dose effects, haemodynamic and hormone recordings were carried out eight times (at 0830, 1000, 1100, 1300, 1500, 
Table 1 Clinical details

\begin{tabular}{lllll}
\hline Case No. & Age $(y)$ & Sex & Aetiology of heart failure & Previous vasodilator treatment \\
\hline 1 & 58 & M & Hypertension, & \\
2 & 62 & coronary artery disease & Prazosin \\
3 & 59 & M & Dilated cardiomyopathy & Nil \\
4 & 48 & Coronary artery disease & Prazosin \\
5 & 70 & Coronary artery disease & Prazosin \\
6 & 48 & Dilated cardiomyopathy & Isosorbide dinitrate \\
7 & 61 & F & Coronary artery disease & Prazosin \\
8 & 66 & & Coronary artery disease & Coronary artery disease, \\
hypertension & Prazosin \\
\hline
\end{tabular}

Table 2 Follow-up data

\begin{tabular}{|c|c|c|c|c|c|c|c|c|c|}
\hline \multirow[t]{2}{*}{ Case No. } & \multicolumn{2}{|c|}{$\begin{array}{l}\text { NYHA Functional } \\
\text { Class }\end{array}$} & \multicolumn{2}{|c|}{$\begin{array}{l}\text { Radionuclide left } \\
\text { ventricular ejection } \\
\text { fraction }(\%)\end{array}$} & \multicolumn{2}{|c|}{$\begin{array}{l}\text { Exercise duration } \\
\text { (min) }\end{array}$} & \multicolumn{2}{|c|}{$\begin{array}{l}\text { Frusemide dose } \\
(m g / d)\end{array}$} & \multirow[t]{2}{*}{$\begin{array}{l}\text { Enalapril dose } \\
(m g / d)\end{array}$} \\
\hline & Before & After & Before & After & Before & After & Before & After & \\
\hline $\begin{array}{l}1 \\
2 \\
3 \\
4 \\
5 \\
6 \\
7 \\
8 \\
\text { Mean } \\
\text { SEM } \\
\text { p }\end{array}$ & $\begin{array}{l}\text { III } \\
\text { II } \\
\text { II } \\
\text { III } \\
\text { IV } \\
\text { III } \\
\text { III } \\
\text { IV } \\
3.0\end{array}$ & $\begin{array}{l}\text { II } \\
\text { II } \\
\text { II } \\
\text { II } \\
\text { III } \\
\text { II } \\
\text { II } \\
\text { II } \\
2 \cdot 1\end{array}$ & $\begin{array}{c}31 \\
\overline{11} \\
13 \\
24 \\
26 \\
8 \\
15 \\
18.3 \\
\pm 3.5 \\
0.05\end{array}$ & $\begin{array}{l}39 \\
12 \\
15 \\
28 \\
36 \\
6 \\
30 \\
23 \cdot 7 \\
\pm 5 \cdot 2 \\
10\end{array}$ & $\begin{array}{r}16.5 \\
9.0 \\
26.0 \\
- \\
2.5 \\
22.3 \\
24.5 \\
0.9 \\
14.5 \\
\pm 4.3\end{array}$ & $\begin{array}{r}17.5 \\
12.0 \\
21.7 \star \\
- \\
6.8 \\
21.5 \\
18.1 \\
8.3 \\
15.1 \\
\pm 2.5\end{array}$ & $\begin{array}{r}160 \\
40 \\
40 \\
80 \\
250 \\
250 \\
500 \\
250 \\
196 \\
\pm 58\end{array}$ & $\begin{array}{r}40 \\
20 \\
0 \\
20 \\
500 \\
250 \\
500 \\
120 \\
181 \\
\pm 80\end{array}$ & $\begin{array}{l}10 \\
20 \\
20 \\
10 \\
10 \\
20 \\
10 \\
10\end{array}$ \\
\hline
\end{tabular}

Results are shown before enalapril, and at follow-up after four to eight weeks of enalapril treatment (after).

*This patient developed claudication during treadmill exercise after introduction of enalapril. NS denotes not statistically significant.

1700,1900 , and 2100 hours) on the first day of enalapril $(5 \mathrm{mg})$ treatment, and for comparison at identical times on the preceding control (pre-enalapril) day. On all other study days including the first control day, these measurements were performed at 0830,1130 , and 1530 hours. Plasma hormone measurements were carried out using $10 \mathrm{ml}$ blood for each sample. At 0830 hours daily, $5 \mathrm{ml}$ blood was drawn for plasma sodium and potassium measurements (flame photometry). Digoxin and frusemide (in six patients) were taken immediately after $\mathbf{0 8 3 0}$ hours recordings.

A full clinical assessment which included physical examination, New York Heart Association (NYHA) Functional Classification, maximum exercise capacity, ${ }^{5}$ and resting technetium cardiac scan was carried out one week before the invasive study and again four to eight weeks after its completion during maintenance enalapril treatment.

\section{STATISTICS}

Repeated measures analyses of variance were performed for all variables. For indices showing significant variation between days, further comparisons using $t$ tests with appropriate mean square error terms from analysis of variance were performed to determine when these changes occurred. Results are presented as mean \pm SEM.

\section{Results}

All but one subject (case 1 Table 1) completed the procedure. This patient developed Staphylococcus aureus septicaemia from a contaminated catheter on the final day. The septicaemia responded rapidly to antibiotics. The results in this patient are included in data analysis for the first dose effect of enalapril, and also for follow-up since enalapril was reintroduced without complications. The pattern of hormone and haemodynamic responses during the three days of intensive monitoring was similar in patients who continued frusemide treatment to those in whom diuretics had been withdrawn; thus all results are combined.

\section{FIRST DOSE EFFECTS}

The first dose effects of enalapril are shown in Fig. 1 and 2. After $5 \mathrm{mg}$ enalapril, plasma angiotensin II levels had declined by two hours and remained below control day values thereafter (Fig. 1). A reciprocal pattern in plasma renin activity was observed though at 24 hours the levels were not significantly different from those on the control day (Fig. 1). Plasma aldosterone levels were not altered. Plasma noradrenaline tended to increase during the first eight hours of the control day, whereas after enalapril this rise was attenuated such that at eight hours the levels from the 
two days were significantly different (Fig. 1). Plasma adrenaline and cortisol levels were unaffected by enalapril.

Cardiac index was not altered significantly by the first dose of enalapril, but heart rate declined (Fig. 2) with a consequent rise in stroke index. Systemic vascular resistance and mean arterial pressure declined by four hours and remained below control day values until the 8th to 12th hours (Fig. 2). Pulmonary artery end-diastolic pressure and mean pulmonary artery

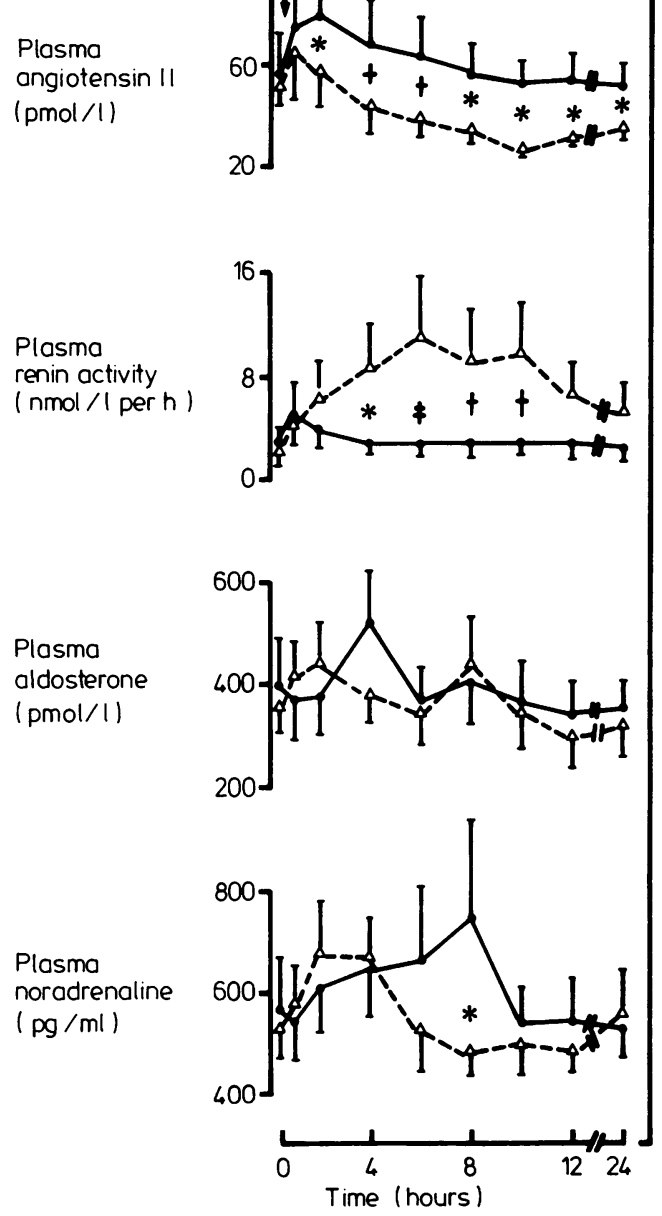

Fig. 1 Plasma hormone levels (mean $\pm S E M$ ) in eight patients with heart failure on a control day (closed symbols) and after $5 \mathrm{mg}$ enalapril (open symbols). Enalapril was administered at $0900 \mathrm{~h}$ after baseline measurements at $0830 \mathrm{~h} .{ }^{\star} p<0.05$; $\dagger p<0.01 ; \ddagger p<0.005$. pressure also fell, the peak effect occurring at six to eight hours. All haemodynamic indices had returned to control day values 24 hours after the first dose of enalapril (Fig. 2).

The degree of activation of the renin-angiotensin system and the sympathetic system on control days predicted haemodynamic responses to the first dose of enalapril. Thus, baseline levels of angiotensin II (drawn at 0830 hours on days 2 and 3) correlated in a positive fashion with maximum increases in stroke

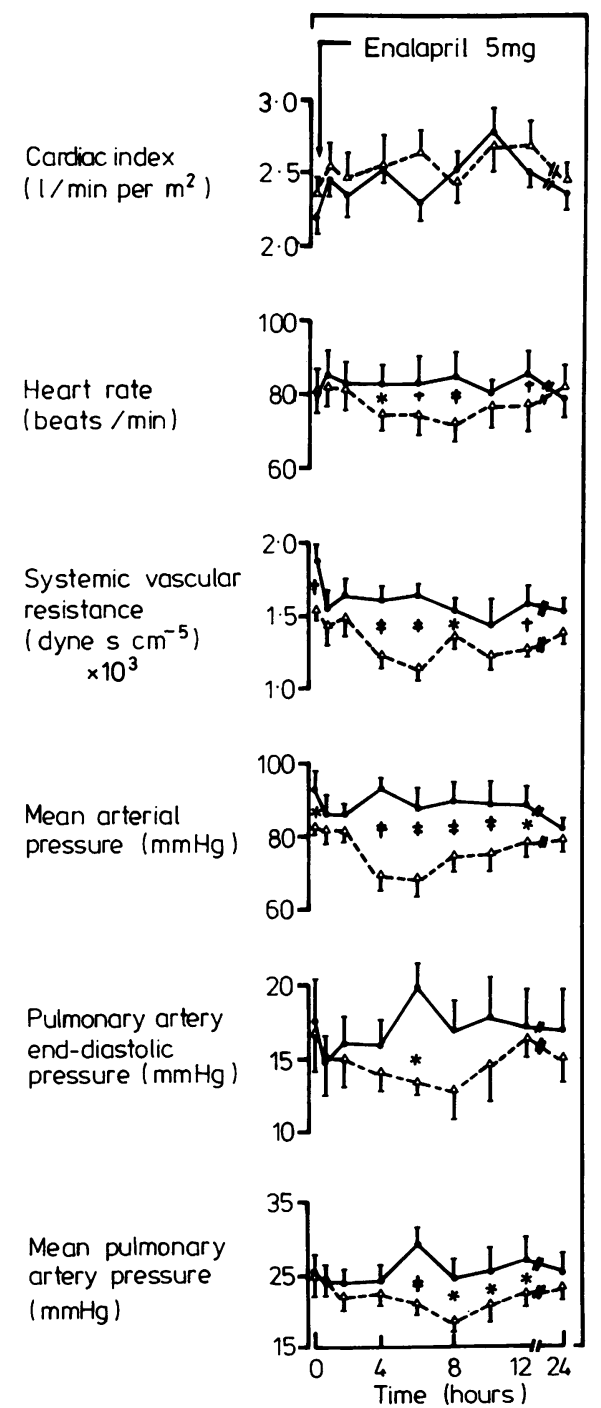

Fig. 2 Haemodynamic indices (mean $\pm S E M$ ) on a control day (closed symbols) and the following day after $5 \mathrm{mg}$ enalapril (open symbols) in eight heart failure patients. After baseline recordings at $0830 \mathrm{~h}$ enalapril was given at $0900 \mathrm{~h} .{ }^{\star} p<0.05$; $\dagger p<0.01$; $\ddagger p<0.005$. 
index $(r=0.73)$, and inversely with changes in systemic vascular resistance $(r=-0.83)$, pulmonary artery end-diastolic pressure $(r=-0.83)$, and mean pulmonary artery pressure $(\mathrm{r}=-0.80 ; \mathrm{p}<0.05$ to $<0.001)$. Likewise, baseline noradrenaline related closely to the rise in stroke index $(r=0.69)$ and the fall in pulmonary artery end-diastolic pressure $(r=-0.80)$ and mean pulmonary artery pressure $(\mathrm{r}=-0.78, \mathrm{p}<0.05$ to $<0.01)$.

\section{INCREMENTAL DOSE EFFECTS}

The effects of increasing doses of enalapril on hormones and haemodynamics are shown in Fig. 3 and 4. Data from the first two control days were combined and compared with time matched results on the subsequent days of enalapril treatment. It should be noted that the 24 hour post-dose values in Fig. 3 and 4 represent baseline recordings before the next dose of enalapril. It can be seen from 24 hour post-dose results that daily baseline ( 0830 hours) values for angiotensin II (Fig. 3) and systemic vascular resistance (Fig. 4) decreased. A similar trend downward was seen for plasma aldosterone and noradrenaline (Fig. 3) and for arterial pressure and right heart pressures (Fig. 4), but levels of statistical significance were not attained. In contrast, the daily baseline cardiac index increased (Fig. 4), a trend also seen for plasma renin activity, stroke index, and heart rate (not statistically significant).

When results two and a half and six and a half hours after enalapril were pooled and compared with time matched data during the control period, dose related decrements were seen for angiotensin II and systemic vascular resistance, while reciprocal increments in plasma renin activity, cardiac index, and stoke index were evident (Fig. 3 and 4). These changes were less clearly related to the dose of enalapril if daily 0830 hours values (rather than time matched levels) were taken as a baseline, since as already noted the latter values themselves were not stable (left hand panel, Fig. 3 and 4), presumably as a consequence of enalapril administration. For other indices including arterial pressure and pulmonary artery pressures, a prominent change occurred with $5 \mathrm{mg}$ enalapril and subsequent increases in enalapril dose were without additional effect (Fig. 4).

Cortisol levels in plasma and urine were not altered by enalapril. Urine aldosterone excretion, however, decreased in a stepwise fashion with each increase of enalapril dose (Fig. 5).

\section{ELECTROLYTE AND RENAL EFFECTS}

Plasma sodium concentration decreased transiently while plasma potassium rose steadily during enalapril administration (Fig. 5). Urine sodium excretion on control days (96.6 $\pm 14.8 \mathrm{mmol} /$ day) was close to diet- ary intake, but declined throughout the three days of enalapril treatment when cumulative balance was positive overall by an average of $21 \mathrm{mmol} /$ day per patient. A similar trend was seen for potassium (Fig. 5), and the positive cumulative balance during three days of enalapril treatment was on average $15 \mathrm{mmol} /$ day per patient. Endogenous creatinine clearance showed a tendency to increase during the treatment phase (Fig. 5), but this was not statistically significant. Body weight remained steady.
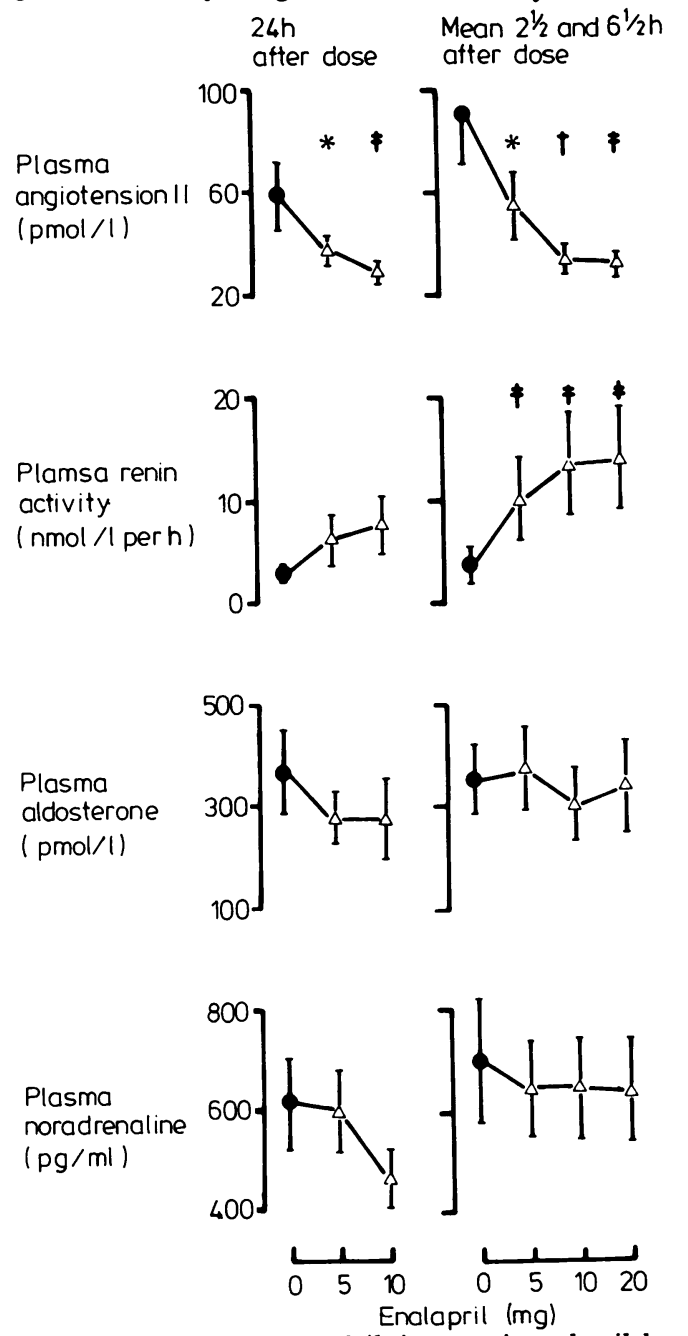

Fig. 3 Hormone responses to daily increases in enalapril dose in seven patients with heart failure (mean $\pm S E M)$. On the left panel, results from $0830 \mathrm{~h}$ on two control days are combined (closed symbols) and compared with time matched recordings 24 hours after $5 \mathrm{mg}$ and $10 \mathrm{mg}$ enalapril (open symbols). Values at two and $a$ half and six and $a$ half hours after enalapril (open symbols) are combined and compared with mean time matched levels from two control days (closed symbols) on the right half of the figure. ${ }^{\star} p<0.05 ; \dagger p<0.01 ; \ddagger p<0.005$. 

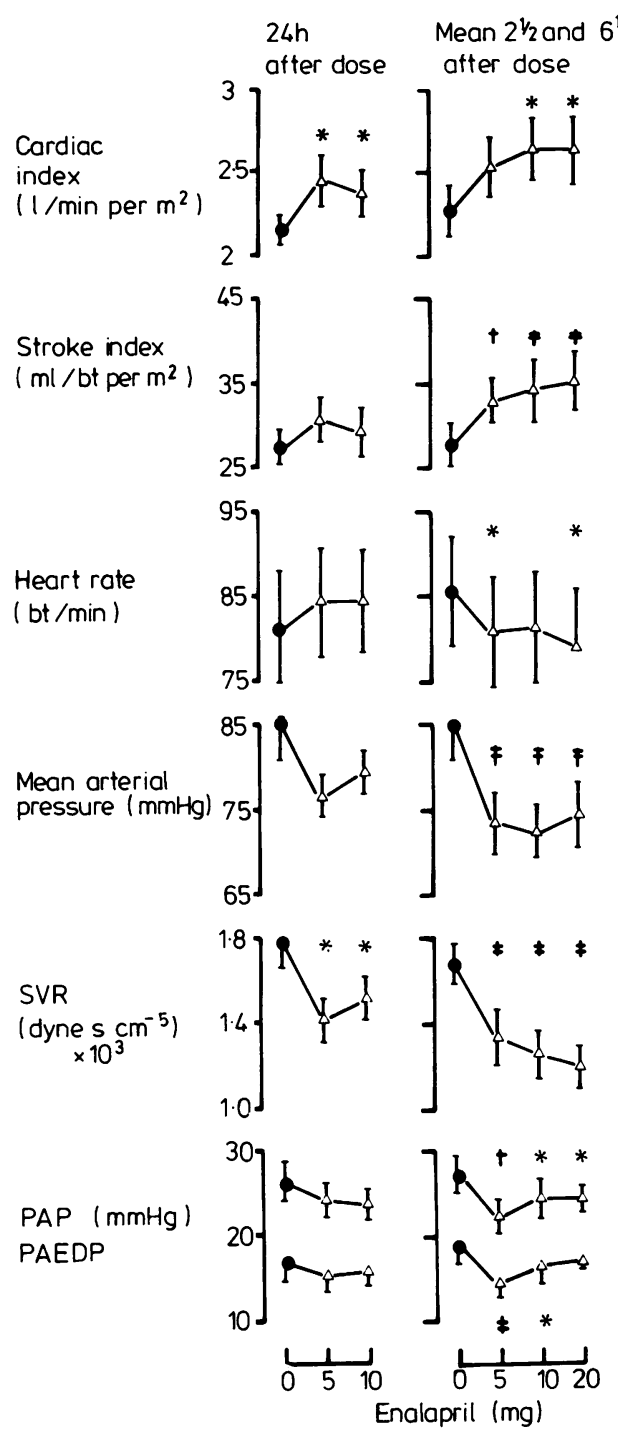

Fig. 4 Haemodynamic responses to increasing doses of enalapril in seven heart failure patients (mean $\pm S E M$ ). In the left half of the figure, results from $0830 \mathrm{~h}$ on two control days are combined (closed symbols) and compared with time matched recordings 24 hours after $5 \mathrm{mg}$ and $10 \mathrm{mg}$ enalapril (open symbols). Results obtained two and $a$ half and six and $a$ half hours after enalapril (open symbols) are combined and compared with mean time matched levels from two control days (closed symbols) on the right half of the figure. SVR denotes systemic vascular resistance. $\overline{P A P}$ denotes mean pulmonary arterial pressure. PAEDP denotes pulmonary artery end-diastolic pressure. ${ }^{\star} p<0.05 ; \dagger p<0.01 ; \ddagger p<0.005$.

FOLLOW-UP

Enalapril therapy ( 10 to $20 \mathrm{mg} /$ day) was continued in all subjects upon completion of the in-patient study. Reintroduction of frusemide was required on clinical grounds in two patients in whom it was initially withdrawn, but the dose needed was less than that before enalapril (Table 1). In the group of six whose frusemide was not withheld, the dose required at follow-up was decreased in three, increased in one, and unchanged in two (Table 2). After four to eight weeks of enalapril, the NYHA Functional status had improved by two classes in one patient, one class in five patients, while two remained unchanged in Class II (Table 2). Clinical variables of heart failure improved in all Class III and IV patients.

Overall, there was no statistically significant improvement in treadmill exercise performance. Patients in whom initial exercise tolerance was most severely limited showed an increase in exercise capacity during continued enalapril treatment (Table 2). On the contrary, patients whose exercise performance was less impaired had unchanged or reduced treadmill performance with enalapril (Table 2 ). In case 3 , the decline in exercise tolerance was the result of the appearance of leg muscle claudication after the introduction of enalapril.

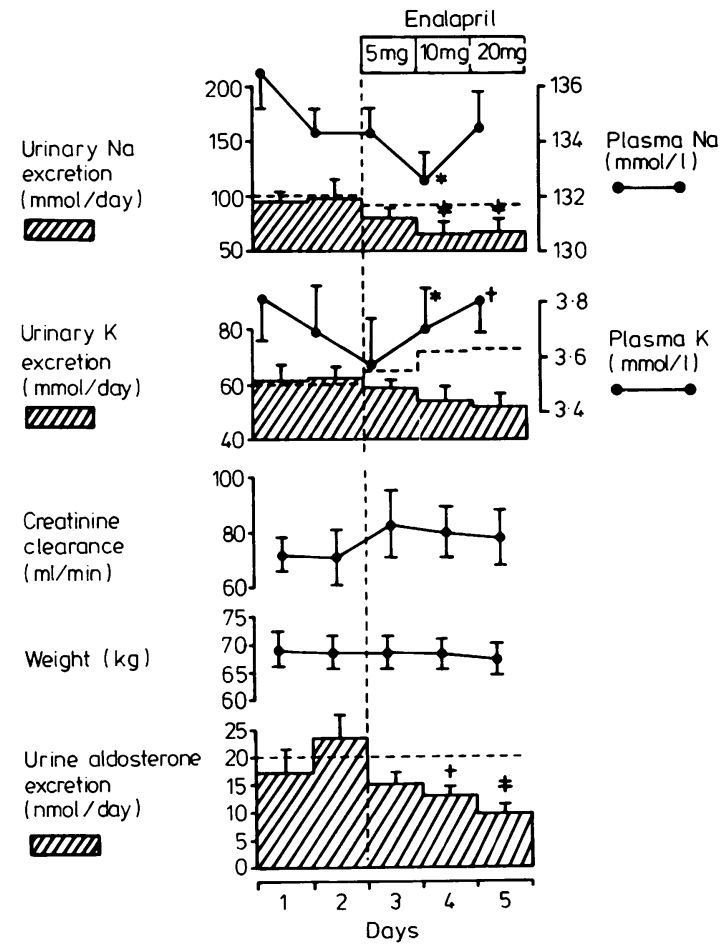

Fig. 5 Electrolytes, renal function, and aldosterone excretion before and during the introduction of enalapril in seven patients (mean $+S E M)$. Horizontal interrupted lines represent mean dietary sodium and potassium intake, and the mean aldosterone excretion for the two control (pre-enalapril) days. ${ }^{\star} p<0.05$; $\dagger p<0.01 ; \ddagger p<0.005$. 
Radionuclide left ventricular ejection fraction was initially $18 \cdot 3 \pm 3.5 \%$ and after four to eight weeks of enalapril treatment had increased to $23 \cdot 7 \pm 5 \cdot 2 \%$ $(0.05<p<0.10)$. The change in ejection fraction correlated closely with the change in exercise time over the four to eight week period of follow-up $(r=0.81$, $\mathrm{p}<0.05$ ).

Apart from case 3 who developed intermittent claudication, no side effects were encountered during the study. No abnormality developed on regular biochemistry (SMAC-11) and haematology screening, and proteinuria was not observed.

\section{Discussion}

Converting enzyme inhibition has brought a new dimension to the management of cardiac failure. Captopril, the only currently available oral converting enzyme inhibitor, has proved effective in patients who were resistant to conventional treatment. ${ }^{2}$ Though side effects are not common with captopril, potentially serious complications have been reported. 6 Enalapril (MK-421), a member of a new group of converting enzyme inhibitors which lack a mercapto function and are characterised by weak chelating properties, has recently been synthesised ${ }^{3}$ and used sucessfully in hypertension. ${ }^{4}$ Preliminary data suggest it is longer acting than captopril in hypertension, ${ }^{4}$ and so far serious side effects have not been observed. We now report short-term hormonal, haemodynamic, and electrolyte responses to enalapril in patients with cardiac failure studied under carefully controlled conditions.

The first dose $(5 \mathrm{mg})$ of enalapril induced a sustained fall in plasma angiotensin II, heart rate, systemic vascular resistance, arterial pressure, and pulmonary artery pressure, and a reciprocal rise in plasma renin activity. These changes are similar to those reported with captopril. ${ }^{12}$ The onset of action and the maximum effects were delayed, however, compared with captopril, ${ }^{7}$ and the decline in circulating angiotensin II was more prolonged after $5 \mathrm{mg}$ enalapril than with larger doses of captopril. ${ }^{8}$ Angiotensin II levels 24 hours after the first dose of enalapril were still lower than time matched levels on the control day, whereas most haemodynamic indices had earlier returned to baseline. Control mechanisms other than angiotensin II might account for this temporal dissociation-including sympathetic system activity which, as judged by plasma noradrenaline levels, was altered only transiently by the initial dose of enalapril. Unmeasured factors such as bradykinin and prostaglandins may also have contributed to the pattern of haemodynamic changes we observed.

Angiotensin II levels were lower and plasma renin activity higher after the larger doses $(10 \mathrm{and} 20 \mathrm{mg}$ ) of enalapril than after $5 \mathrm{mg}$ of the drug. This was so for hormone measurements taken two and a half and six and a half, as well as 24 hours after enalapril (Fig. 3). These results suggest that inhibition of converting enzyme is more complete and perhaps of longer duration with the larger of the doses used. Similar dose related changes were seen for cardiac index, stroke index, and systemic vascular resistance, whereas right heart pressures reached their nadir after $5 \mathrm{mg}$ of enalapril (Fig. 4). From these data, it appears that $10 \mathrm{mg}$ and $20 \mathrm{mg}$ of enalapril may be more effective than $5 \mathrm{mg}$, though the latter dose may ultimately prove to be as effective in long term treatment if cumulative effects occur. Of practical importance is the relatively long duration of action of enalapril with $5 \mathrm{mg}$ and also $10 \mathrm{mg}$ and $20 \mathrm{mg}$. This prolonged action should allow its administration once, or at most, twice daily in heart failure.

Our results show objective haemodynamic improvement in the short term during enalapril treatment. The raised systemic vascular resistance was reduced as a consequence of the decline in circulating angiotensin II, and perhaps also in part as a consequence of sympathetic withdrawal as indicated by the fall in circulating noradrenaline levels and the reduction in heart rate. Cardiac index overall increased during the study, while right heart pressures decreased-presumably as a result of improved left ventricular performance but perhaps partly because of a decline in cardiac preload. The most striking haemodynamic improvements in response to the first dose of enalapril were seen in subjects in whom activation of the renin angiotensin system and sympathetic system was most intense. These observations suggest that the drug will be particularly effective in patients with severe cardiac failure, at least in the short term.

During the first three days of enalapril treatment, we observed a positive cumulative sodium balance. Our study does not clarify what factor(s) among the many that contribute to the renal regulation of sodium excretion dictated this sodium retention. Whatever the explanation, it appears to be of little consequence in the longer term since frusemide requirements were reduced or unchanged in all but one patient after four to eight weeks of treatment. As has been reported with captopril, 1 a positive cumulative potassium balance and a rise in plasma potassium were seen. We suggest that plasma potassium be monitored when enalapril treatment is initiated. Despite the decline in arterial pressure, endogenous creatinine clearance tended to increase during the three day phase of intensive monitoring. Similar improvements in glomerular filtration rate have been documented with captopril treatment in patients with severe resistant heart failure. ${ }^{2}$ It remains to be seen what effect long 
term enalapril treatment has on renal function.

It may appear surprising that plasma aldosterone levels did not fall after the first dose of enalapril, especially since we earlier reported the dominant role of angiotensin II in regulating aldosterone in heart failure. ${ }^{9}$ Baseline levels of plasma aldosterone, however, were not raised in most of our patients, in contrast to those studied before the initiation of captopril therapy. ${ }^{9}$ The dependence of aldosterone secretion on angiotensin II presumably relates to the degree of activation of the renin angiotensin system. Where this is relatively minor, as in the present study, blockade of angiotensin II formation might not necessarily result in an acute decline in aldosterone. Nevertheless, aldosterone excretion fell during the three days of incremental enalapril treatment, and a similar (though less impressive) decline in plasma aldosterone was observed. We conclude then that aldosterone secretion was regulated in part by angiotensin II during the present study, but the primacy of the renin angiotensin system was less obvious than in patients with extreme activation of the renin angiotensin system.

Our patients were followed up for four to eight weeks while enalapril treatment was continued. It was apparent from exercise testing, and clinical assessment, that those who initially were more severely limited by cardiac failure showed the most benefit from enalapril therapy. The dose of frusemide was not altered at follow-up in most of these latter subjects. It is conceivable that in reducing the daily dose of frusemide in those with milder degrees of heart failure, we tended to counterbalance any beneficial effects of enalapril.

Short term studies such as ours do not allow extrapolation to long term effects or changes in mortality. Nevertheless, the current data show clear cut short term haemodynamic benefits with the introduction of enalapril therapy. Longer term controlled studies of enalapril in heart failure are warranted.

The study was supported by the Medical Research Council of New Zealand and Merck, Sharp and Dohme. We thank Dr Elisabeth Wells for statistical help.

\section{References}

1 Maslowski AH, Ikram H, Nicholls MG, Espiner EA. Haemodynamic, hormonal, and electrolyte responses to captopril in resistant heart failure. Lancet $1981 ; i ; 71-4$.

2 Dzau VJ, Colucci WS, Williams GH, Curfman G, Meggs L, Hollenberg NK. Sustained effectiveness of converting-enzyme inhibition in patients with severe congestive heart failure. $N$ Engl f Med 1980; 302: 13739.

3 Patchett AA, Harris E, Tristram EW, et al. A new class of angiotensin-converting enzyme inhibitors. Nature 1980; 288: 280-3.

4 Gavras H, Biollaz J, Waeber B, Brunner HR, Gavras I, Davies RO. Antihypertensive effect of the new oral angiotensin converting enzyme inhibitor "MK-421". Lancet 1981; ii: 543-7.

5 Patterson JA, Naughton J, Pietras RJ, Gunnar RM. Treadmill exercise in assessment of the functional capacity of patients with cardiac disease. Am $\mathcal{f}$ Cardiol 1972; 30: 757-62.

6 Vidt DG, Bravo EL, Fouad FM. Captopril. N Engl f Med 1982; 306: 214-20.

7 Ader R, Chatterjee K, Ports T, Brundage B, Hiramatsu B, Parmley W. Immediate and sustained haemodynamic and clinical improvement in chronic heart failure by an oral angiotensin-converting enzyme inhibitor. Circulation 1980; 61: 931-7.

8 Nicholls MG, Ikram H, Espiner EA, Maslowski AH, Scandrett MS, Penman T. Haemodynamic and hormonal responses during captopril therapy for heart failure: acute, chronic and withdrawal studies. Am $\mathcal{F}$ Cardiol 1982; 49: 1497-501.

9 Nicholls MG, Espiner EA, Ikram H, Maslowski AH, Lun S, Scandrett MS. Angiotensin II is more potent than potassium in regulating aldosterone in cardiac failure: evidence during captopril therapy. $\mathcal{F}$ Clin Endocrinol Metab 1981; 52: 1253-6.

Requests for reprints to Dr Drew Fitzpatrick, Cardiology Department, The Princess Margaret Hospital, Cashmere Road, Christchurch 2, New Zealand. 